\title{
Antioxidant intake and adult-onset wheeze: a case-control study
}

\author{
C. Bodner*, D. Godden*,*, K. Brown ${ }^{\S}$, J. Little ${ }^{+}$, S. Ross ${ }^{\#}$, A. Seaton* \\ on behalf of Aberdeen WHEASE Study Group
}

\begin{abstract}
Antioxidant intake and adult-onset wheeze: a case-control study. C. Bodner, D. Godden, K. Brown, J. Little, S. Ross, A. Seaton on behalf of Aberdeen WHEASE Study Group. (C) ERS Journals Ltd 1999.

ABSTRACT: An increase in prevalence of wheezing illness in the UK has coincided with a reduction in the consumption of natural antioxidants, which may modulate the lung's response to oxidant stress, limiting the expression of airway inflammation and respiratory symptoms. The hypothesis that intakes and plasma levels of natural antioxidants would be determinants of adult-onset wheezing illness was tested.

A nested case-control study was conducted in 94 cases with adult-onset wheeze and 203 controls aged 39-45 yrs identified in a 30-yr follow-up survey. Antioxidant intake was measured by a food frequency questionnaire, and plasma and red cell measurements of antioxidant status were obtained. Outcome measures were onset of wheeze since age 15 yrs (ever wheeze) and wheeze occurring in the past 12 months (current wheeze).

After adjusting for the effects of smoking, socioeconomic status, atopy, family history of atopic disease and total energy intake, intakes of vitamin $E$ (odds ratio $(\mathrm{OR})=\mathbf{4 . 0 2}$ for low compared to high tertile of intake) and plasma levels of ascorbate $\left(\mathrm{OR}=0.98\right.$ per unit) and $\alpha$-tocopherol:triglyceride ratio $\left(\mathrm{OR}=0.34\right.$ per $\log _{\mathrm{e}}$ unit) were inversely related to adult-onset wheeze. In analyses stratified by social class and smoking, intakes of vitamin $C$ and $E$ and plasma levels of ascorbate and $\alpha$-tocopherol:triglyceride ratio were inversely related to current wheeze in the manual social class and among current smokers. No independent associations of vitamin $A, \beta$-carotene or total plasma antioxidant capacity were found.

The results support the hypothesis that deficiencies of vitamins $\mathrm{C}$ and $\mathrm{E}$ are associated with wheezing symptoms. Smokers in the manual social class are particularly susceptible to these effects.

Eur Respir J 1999; 13: 22-30.
\end{abstract}

*Dept of Environmental and Occupational Medicine, ${ }^{+}$Dept of Medicine and Therapeutics, "Health Services Research Unit, University of Aberdeen, Aberdeen, UK. Dept of Thoracic Medicine, Aberdeen Royal Infirmary, Aberdeen, UK. ${ }^{\S}$ Rowett Research Institute, Bucksburn, Aberdeen, UK.

Correspondence: C. Bodner, Dept of Environmental and Occupational Medicine, University of Aberdeen, Aberdeen, AB25 2ZD, UK. Fax: 441224404943

\section{Keywords: Adult onset antioxidants asthma epidemiology obstructive lung diseases vitamins $\mathrm{C}$ and $\mathrm{E}$}

Received: July 91997

Accepted after revision September 31998

This study was supported by grants from the National Asthma Campaign, the Medical Research Council and Aberdeen Royal Hospitals Trust. C. Bodner received support from the Canadian Lung Association.
The epithelial lining of the respiratory system, by virtue of its large surface area and its roles in gas exchange and host defence, is vulnerable to oxidant damage [1]. The toxicity of oxidants, which are directly inhaled or generated through inflammatory processes such as the response to allergen, is normally balanced by the protective activity of an array of endogenous antioxidant defence systems which may be functionally dependent on an adequate supply of nutritional antioxidants. A dramatic rise in the prevalence of wheezing illnesses among young people occurred in Britain in the period 1960-1990 [2, 3] during which a reduction in intake of foods which contain natural antioxidants occurred [4]. It has been postulated that these events may be causally associated, a reduction in antioxidant intake leading to the development of wheezing illness in susceptible individuals exposed to oxidants or allergens [5]. Epidemiological evidence is accruing to indicate that low intake of antioxidant nutrients such as vitamins $\mathrm{C}, \mathrm{E}$ and A may be associated with reduced lung function [6-9] and chronic respiratory symptoms $[10,11]$. In a population with seasonal symptoms, an inverse association bet-

WHEASE Study Group members: J.G. Douglas, J. Legge, J.A.R. Friend. ween vitamin $\mathrm{C}$ intake and bronchial reactivity has been reported [12]. High vitamin $\mathrm{E}$ intake was found to have a protective effect against the onset of asthma in adult life in a national cohort of nurses in the USA [13].

To investigate further the hypothesis that deficiencies in nutritional antioxidants may be independent determinants of adult-onset wheeze, a group of cases and controls derived from a cohort of middle-aged subjects who were identified first as children in a random community survey in 1964 were studied. Diet was assessed by means of a food frequency questionnaire (FFQ) and blood levels of nutritional antioxidants, total antioxidant enzyme activity and indices of free-radical-mediated damage were measured. This paper describes the relationships of these factors to the presence of adult-onset wheeze.

\section{Methods}

\section{Subjects}

A nested case-control study among participants in a 30yr follow-up survey was conducted in the Grampian Region of Scotland. Subjects had originally been identified in 1964 by a random one in five sample of all children aged 
$10-14$ yrs who were then in primary school in the city of Aberdeen. Among the 2,511 children whose parents were interviewed in 1964, 121 were classified as having had asthma, 167 as having had wheeze in the presence of upper respiratory infections, and 2,223 as having had no respiratory symptoms [14]. The outcome in middle age (i.e. age $34-40$ yrs) for the 288 symptomatic subjects, together with 167 comparison subjects randomly selected from those who were asymptomatic as children has been reported $[15,16]$. The remaining 2,056 individuals, now aged 39-45 yrs, who had no childhood wheeze were sought to contact. Among the 1,542 respondents to a follow-up postal survey, 177 (11.5\%) reported adult-onset wheeze, defined as a positive response to the question "Have you ever had attack of wheezing or whistling in the chest on or after age 15 yrs?" [17]. In a nested case-control study involving all 117 cases with adult-onset wheeze who lived locally and 277 controls randomly selected from among the respondents with no wheeze who lived locally, adultonset wheeze was associated with low socioeconomic status, current smoking, positive atopic status and positive family history of atopic disease [18]. The present study addresses the role of nutritional factors in these subjects. Ethical approval was obtained from the Grampian Health Board and the University of Aberdeen Joint Ethical Committee and all participants gave written informed consent.

\section{Protocol}

Cases and controls were contacted in random order over a seven-month period from April to October 1995. Information about respiratory symptoms, smoking habit, family history of atopic disease and occupation was obtained by interview and height and weight were measured. Subjects were asked to complete a self-administered FFQ, developed and validated in Scottish populations, which enquired about the usual frequency of consumption of all major food types over the previous year and about the use of vitamin supplements [19]; questionnaires were checked for completeness.

Measurement of atopy. Skin sensitivity to house dust mite (Dermatophagoides pteronyssinus), cat hair and mixed grass pollens with $50 \%$ glycerine negative control (Dome/Hollister-Stier, Spokane, WA, USA) was estimated by skin-prick tests [20]. A positive test was defined as a wheal diameter of $3 \mathrm{~mm}$ or more greater than the negative control measured $10 \mathrm{~min}$ after inoculation [16]. Venous blood samples of $10 \mathrm{~mL}$ were taken for allergen-specific and total immunoglobulin (Ig)E. Specific IgE tests for house dust mite, cat and mixed grass pollen were performed by a standard radioallergosorbent test (RAST) technique (Phadiotop; Pharmacia Diagnostics, Milton Keynes, UK). RAST results for individual allergens were defined as positive when the RAST class was one or greater (i.e. $\geq 0.35 \mathrm{IU} \cdot \mathrm{mL}^{-1}$ ) and negative when the RAST response was zero (i.e. $<0.35 \mathrm{IU} \cdot \mathrm{mL}^{-1}$ ). Skin and specific IgE tests were expressed as positive if at least one antigen showed a positive result. Total IgE was determined by paper radioimmunosorbent test (Pharmacia Diagnostics) [16] and levels $>120 \mathrm{IU} \cdot \mathrm{mL}^{-1}$ were considered as positive.
Analytical methods for blood samples. Blood was withdrawn from the antecubital vein of each subject into ethylenediaminetetraacetic acid (EDTA)-treated and plain tubes, stored immediately at $4{ }^{\circ} \mathrm{C}$ and processed within $12 \mathrm{~h}$ of collection. Subjects were asked to avoid taking fruit and fruit juice for $6 \mathrm{~h}$ prior to blood sampling. Prior to processing, EDTA tubes were rolled for a minimum of $5 \mathrm{~min}$. Blood was centrifuged $(1,500 \times \mathrm{g}$, $4{ }^{\circ} \mathrm{C}, 15 \mathrm{~min}$ ), plasma was removed and the red cells were washed three times in iso-osmotic phosphate-buffered saline (PBS) $(50 \mathrm{mM}, \mathrm{pH} 7.4)$ and resuspended to the original volume. Plasma for vitamin $\mathrm{C}$ (ascorbate) analysis was diluted with $10 \%$ (w/v) metaphosphoric acid and stored with the remaining plasma and red blood cells at $-70^{\circ} \mathrm{C}$. Erythrocyte susceptibility to peroxidation was determined in $100 \mu \mathrm{L}$ fresh washed, resuspended red cells diluted with $900 \mu \mathrm{L}$ PBS containing $2 \mathrm{mM}$ sodium azide. The cells were incubated with $1.5 \%$ hydrogen peroxide for $1 \mathrm{~h}$ at $37^{\circ} \mathrm{C}$, after which the reaction was stopped by the addition of $1 \mathrm{~mL} 20 \%$ trichloroacetic acid. The remaining suspensions were frozen slowly with $2 \%$ butylated hydroxytoluene to $-70^{\circ} \mathrm{C}$ prior to final analysis. Haemoglobin concentrations were determined using the cyanmethaemoglobin method. Plasma concentrations of vitamin A (retinol), vitamin $\mathrm{E}$ ( $\alpha$-tocopherol), and $\beta$-carotene were determined by nor-mal phase high-pressure liquid chromatography (HPLC) [21] using a Spherisorb $5 \mu \mathrm{m}$ silica column (Alltech, Carnforth, UK) with hexane and 1,4dioxan as the mobile phase. Concentrations were determined by reference to external standards. Plasma ascorbate concentration was measured using an enzymatic, colorimetric assay based on the method of BEUTLER [22] and adapted for the Roche Cobas Fara autoanalyser (F. Hoffman-La Roche \& Co. Ltd., Basle, Switzerland). Plasma total cholesterol and triglycerides were analysed on the Roche Cobas Fara autoanalyser using kits from Roche and Sigma (Sigma, Dorset, UK). Total radicaltrapping antioxidant parameter (TRAP) expressed as Trolox equivalent antioxidant capacity (TEAC) was measured in plasma using a commercially available kit [23] (Randox Laboratories, Co Antrim, UK). Concentrations of lipid peroxides in plasma were estimated with a test kit [24] (Bioxytech, Bonneuil Sur Marne Cedex, France). This method was also used to measure the extent of erythrocyte susceptibility to peroxidation in vitro in the previously frozen suspensions. Cytosolic glutathione peroxidase activity was determined using hydrogen peroxide as substrate by the coupled method of PAGLIA and VALENTINE [25], where one unit of glutathione peroxidase is defined as that which oxidizes 1 mole of reduced nicotinamide adenine dinucleotide phosphate $(\mathrm{NADPH}) \cdot \mathrm{min}^{-1}$ in the assay system at $\mathrm{pH} 7.6$ with 5 $\mathrm{mM}$ reduced glutathione $(\mathrm{GSH})$, and modified for use on the Roche Cobas Fara autoanalyser.

\section{Data analysis}

Social class, based on the subject's own occupation, was defined as manual or non-manual using the 1991 UK Standard Occupational Classification. Atopic status was expressed as a cumulative variable, summing the positive measures. For family history of atopic disease, each occurrence of asthma, eczema or hayfever in parents and 
siblings was counted and a variable categorized as no affected, one affected and more than one affected relative.

Mean energy intake to calculated basal metabolic rate ratios were calculated to identify possible bias in reported intakes [26]. Daily intakes of specific nutrients were estimated by multiplying the frequency of consumption by standard portion sizes [27] and by the nutrient content of the food items using data from the UK National Nutrient Databank [28]. Intake from supplements was included in the estimates. The nutrient intake values were adjusted for total energy intake by the nutrient residuals technique [29] and classified into tertiles based on the distribution of intake among all subjects [30]. Natural log transformed values for the dietary antioxidants and total energy were used to compare intakes between cases and controls and to calculate correlations between dietary and plasma values. The ratio of $\alpha$-tocopherol to triglycerides was calculated to adjust for postprandial changes in $\alpha$-tocopherol and triglyceride levels; natural log transformed values were used in the analyses.

Statistical analysis was carried out using SPSS $\mathbb{R}$ ( 6.0 (SPSS Inc., Chicago, IL, USA) and STATA $®$ Release 4 (Stata Corporation, College Station, TX, USA). Correlations between dietary and plasma values were tested by partial correlation analysis, adjusting for total energy intake, body mass index (BMI; calculated as weight $(\mathrm{kg})$ divided by height (m) squared), sex and smoking. For the fat soluble vitamins (A, E and $\beta$-carotene), partial correlation analyses were also adjusted for the effects of lipids (i.e. triglycerides and cholesterol). Intakes and blood values were compared between cases and controls by twosample t-tests and analysis of covariance. The association of wheeze with antioxidant intakes, blood levels and potential confounding variables was assessed by logistic regression analysis. Potential misclassification arising from systematic over- or under-reporting of total intake was accounted for, including adjustment for total energy intake in the models [29]. The independent effects of antioxidant nutrients were estimated among all cases with adult-onset wheeze between age 15 and 45 yrs ("ever" wheeze) according to the prior postal survey [17] and among cases with wheeze in the past 12 months ("current" wheeze) at interview. In view of the potential for intercorrelation between social class, smoking and nutrient intakes, strat- ified analyses were performed by class and smoking habit. The goodness of fit of the logistic regression models was assessed using the test described by HOSMER and LeMEsHow [31]. An adequate fit was obtained for all models reported in this paper.

\section{Results}

Of the 394 subjects who were identified as potentially eligible for the case-control study, 14 individuals (4 cases and 10 controls) had recently moved away from the Grampian Region. Complete interview, atopy and intake data were obtained from 297 (78\%) (including 94 (83\%) cases and $203(76 \%)$ controls) of the remaining 380 subjects with whom contact was established. Blood samples were obtained from 280 (74\%) subjects including $86(76 \%)$ cases and 194 (73\%) controls. Cases and controls who participated did not differ from those who refused to participate in terms of sex, smoking habit or social class. At interview, 13 control subjects reported that they had developed wheezing symptoms since responding to the postal survey; these individuals were excluded from the analysis where current wheeze was the outcome.

The mean ratios of energy intake to basal metabolic rate were 1.40 (SD 0.48) for males and 1.46 (SD 0.41) for females. Dietary intake values were significantly correlated with plasma levels for vitamin $\mathrm{C}(\mathrm{r}=0.42, \mathrm{p} \leq 0.001)$, vita$\min \mathrm{E}(\mathrm{r}=0.34, \mathrm{p} \leq 0.001)$ and $\beta$-carotene $(\mathrm{r}=0.26, \mathrm{p} \leq$ 0.001 ) but not for vitamin A.

Daily energy, total fat and antioxidant vitamin intakes of cases and controls are shown in table 1. Dietary and supplemental sources were included in the antioxidant intake values. Vitamin supplements, containing single or multiple antioxidant nutrients, were being taken daily (one subject took supplements every third day) by a total of 35 $(12 \%)$ subjects (16 cases and 19 controls). Compared with control subjects, cases derived a greater proportion of their energy intake from fats. Cases had significantly lower intakes of vitamin $\mathrm{C}$ and higher intakes of vitamin A compared with controls. There were no significant differences between the groups with regard to total energy intake, $\beta$-carotene and vitamin $\mathrm{E}$. The corresponding plasma concentrations of antioxidants and fats are shown

Table 1. - Distribution of reported daily nutrient intakes, including supplemental sources, (mean \pm SD (median)) among cases and controls

\begin{tabular}{lccccc}
\hline Nutrient & $\begin{array}{c}\text { Number of } \\
\text { supplement users }(\mathrm{n}=35)\end{array}$ & $\begin{array}{c}\text { Median of low } \\
(\text { high) tertiles }\end{array}$ & $\begin{array}{c}\text { Cases } \\
(\mathrm{n}=94)\end{array}$ & $\begin{array}{c}\text { Controls } \\
(\mathrm{n}=203)\end{array}$ & Significance \\
\hline $\begin{array}{l}\text { Energy } \\
\text { kcal } \\
\text { Total fat }\end{array}$ & $1610(2807)$ & $\begin{array}{c}2314 \pm 757 \\
(2225)\end{array}$ & $\begin{array}{c}2185 \pm 721 \\
(1993)\end{array}$ & $\mathrm{p}=0.146^{*}$ \\
$\begin{array}{l}\text { \% energy intake } \\
\text { Vitamin A } \mu \mathrm{g}\end{array}$ & & $29(40)$ & $\begin{array}{c}36.04 \pm 6.40 \\
(35.62)\end{array}$ & $\begin{array}{c}33.87 \pm 6.29 \\
(34.21)\end{array}$ & $\mathrm{p}=0.006^{*}$ \\
& & $439(1568)$ & $\begin{array}{c}1132 \pm 741 \\
(1000)\end{array}$ & $\begin{array}{c}922 \pm 628 \\
(780)\end{array}$ & $\mathrm{p}=0.024^{\dagger}$ \\
$\beta$-carotene $\mu \mathrm{g}$ & 28 & $1053(2853)$ & $\begin{array}{c}2018 \pm 1335 \\
(1782)\end{array}$ & $\begin{array}{c}2012 \pm 1117 \\
(1800)\end{array}$ & $\mathrm{p}=0.220^{\dagger}$ \\
Vitamin C mg & 4 & $51.35(171.05)$ & $\begin{array}{c}106.66 \pm 76.01 \\
(85.7)\end{array}$ & $\begin{array}{c}126.30 \pm 116.91 \\
(97.6)\end{array}$ & $\mathrm{p}=0.018^{\dagger}$ \\
Vitamin E mg & 20 & $5.79(7.93)$ & $7.85 \pm 4.25$ & $\begin{array}{c}12.05 \pm 47.18 \\
(6.88)\end{array}$ & $\mathrm{p}=0.108^{\dagger}$ \\
\end{tabular}

*: between group comparisons were made using t-tests; ${ }^{\dagger}$ : between group comparisons were made with analysis of covariance using $\log _{\mathrm{e}}$ values of the nutrients including adjustment for $\log _{\mathrm{e}}$ of energy intake. 
Table 2. - Distribution of plasma and erythrocyte concentrations (mean \pm SD (median)) among cases and controls

\begin{tabular}{|c|c|c|c|}
\hline & Cases $(n=86)$ & Controls $(n=194)$ & Significance* \\
\hline \multicolumn{4}{|l|}{ Plasma } \\
\hline Retinol $\mu \mathrm{mol} \cdot \mathrm{L}^{-1}$ & $3.65(1.17)$ & $3.46(0.87)$ & $\mathrm{p}=0.133$ \\
\hline$\beta$-carotene $\mu \mathrm{mol} \cdot \mathrm{L}^{-1}$ & $0.41(0.34)$ & $0.53(0.43)$ & $\mathrm{p}=0.023$ \\
\hline Ascorbate $\mu \mathrm{mol} \cdot \mathrm{L}^{-1}$ & $39.77(21.66)$ & $50.67(24.74)$ & $\mathrm{p}<0.001$ \\
\hline$\alpha$-tocopherol $\mu \mathrm{mol} \cdot \mathrm{L}^{-1}$ & $27.03(6.51)$ & $26.02(7.21)$ & $\mathrm{p}=0.267$ \\
\hline Total cholesterol $\mathrm{mmol} \cdot \mathrm{L}^{-1}$ & $5.27(1.12)$ & $5.07(1.01)$ & $\mathrm{p}=0.141$ \\
\hline Triglycerides $\mathrm{mmol} \cdot \mathrm{L}^{-1}$ & $1.91(1.15)$ & $1.55(1.03)$ & $\mathrm{p}=0.010$ \\
\hline$\alpha$-tocopherol:triglyceride ratio $\log _{e}$ & $2.79(0.48)$ & $2.98(0.53)$ & $\mathrm{p}=0.004$ \\
\hline Trolox equivalent antioxidant capacity $\mathrm{mmol} \cdot \mathrm{L}^{-1}$ & $1.70(0.24)$ & $1.71(0.24)$ & $\mathrm{p}=0.777$ \\
\hline Lipid peroxidation $\mu \mathrm{mol} \cdot \mathrm{L}^{-1}$ & $6.85(3.12)$ & $7.24(3.31)$ & $\mathrm{p}=0.351$ \\
\hline \multicolumn{4}{|l|}{ Erythrocytes } \\
\hline Glutathione peroxidase unit. $\mathrm{gHb}^{-1}$ & $41.56(14.19)$ & $40.04(11.40)$ & $\mathrm{p}=0.341$ \\
\hline Erythrocyte lipid peroxidation $\mu \mathrm{mol} \cdot \mathrm{L}^{-1}$ & $247.03(81.90)$ & $246.54(66.92)$ & $\mathrm{p}=0.958$ \\
\hline
\end{tabular}

$\mathrm{Hb}$ : haemoglobin. *: between group comparisons were made using t-tests.

in table 2, together with total plasma antioxidant capacity, measurements of lipid peroxidation and red cell total glutathione. Plasma concentrations of $\beta$-carotene and ascorbate were significantly lower in cases compared to controls. Although plasma $\alpha$-tocopherol concentration did not differ between groups, $\alpha$-tocopherol:triglyceride ratio, accounting for postprandial variation, was significantly lower in cases than controls, reflecting the higher plasma triglyceride concentration observed in cases. Despite significantly lower plasma concentrations of these major antioxidant nutrients, TEAC values, indicative of total plasma antioxidant capacity, were similar between cases and controls, as were levels of lipid peroxidation. The susceptibility of erythrocytes to in vitro hydrogen peroxide-induced lipid peroxidation was also similar between groups, as was activity of cytosolic glutathione peroxidase.

The associations between adult onset wheeze and potential confounding factors are summarized in table 3. Sex was not related to wheeze. The risk of wheeze increased with lower socioeconomic classification, current smok- ing, positive atopic status and a family history of atopic disease.

Table 4 shows the association of wheeze with levels of antioxidant intake. Odds ratios (OR) and 95\% confidence intervals (CI) are given relative to the highest tertile of intake. The independent effects of each antioxidant vitamin were assessed with adjustment for energy intake and for the effects of sex, socioeconomic status, smoking habit, atopic status and family history. Vitamin E intake was inversely associated with current wheeze and there was a significant trend in the OR with decreasing levels of vitamin E. Simultaneous adjustment for vitamin C did not appreciably alter the risk estimates for vitamin E. Exclusion of social class from the model resulted in significant inverse associations of vitamin $\mathrm{C}$ with current wheeze and of vitamin $E$ intake with ever wheeze. No relations of vitamin $A$ or $\beta$-carotene with risk of wheeze were found.

Table 5 shows the association of wheeze with plasma measurements of antioxidant vitamins and lipids, including adjustment for potential confounding factors. Significant inverse associations were seen for ascorbate

Table 3. - Associations between adult onset wheeze and potential risk factors

\begin{tabular}{|c|c|c|c|c|}
\hline & $\begin{array}{c}\text { Cases }(n=94) \\
n(\%)\end{array}$ & $\begin{array}{c}\text { Controls }(n=203) \\
n(\%)\end{array}$ & $\begin{array}{l}\text { Crude OR } \\
(95 \% \mathrm{CI})\end{array}$ & $\begin{array}{c}\text { Mutually adjusted } \\
\text { OR }(95 \% \mathrm{CI})\end{array}$ \\
\hline \multicolumn{5}{|l|}{ Sex } \\
\hline Male & $41(44)$ & $87(43)$ & 1.0 & 1.0 \\
\hline Female & $53(56)$ & $116(57)$ & $0.97(0.59-1.59)$ & $1.04(0.60-1.82)$ \\
\hline \multicolumn{5}{|l|}{ Socioeconomic status } \\
\hline Nonmanual & $36(38)$ & $122(60)$ & 1.0 & 1.0 \\
\hline Manual & $58(62)$ & $81(40)$ & $2.43(1.47-4.01)$ & $2.41(1.37-4.26)$ \\
\hline \multicolumn{5}{|l|}{ Smoking habit } \\
\hline Never-smoked & $28(30)$ & $95(47)$ & 1.0 & 1.0 \\
\hline Former smoker & $24(25)$ & $49(24)$ & $1.66(0.87-3.17)$ & $1.62(0.80-3.28)$ \\
\hline Current smoker & $42(45)$ & $59(29)$ & $2.42(1.35-4.31)$ & $2.05(1.08-3.91)$ \\
\hline \multicolumn{5}{|l|}{ Atopic status } \\
\hline No measures positive & $33(38)$ & $98(50)$ & 1.0 & 1.0 \\
\hline Only one measure positive & $16(18)$ & 37 (19) & $1.28(0.63-2.60)$ & $1.35(0.63-2.90)$ \\
\hline Two measures positive & $24(28)$ & $46(23)$ & $1.55(0.82-2.91)$ & $1.39(0.70-2.78)$ \\
\hline Three measures positive & $14(16)$ & $16(8)$ & $2.60(1.15-5.89)$ & $2.92(1.18-7.23)$ \\
\hline \multicolumn{5}{|l|}{ Family history of atopy } \\
\hline No family history & $40(44)$ & $131(67)$ & 1.0 & 1.0 \\
\hline One affected & $26(29)$ & $45(23)$ & $1.89(1.04-3.44)$ & $1.84(0.97-3.46)$ \\
\hline More than one affected & $25(27)$ & $19(10)$ & $4.31(2.15-8.62)$ & $4.81(2.29-10.09)$ \\
\hline
\end{tabular}

OR: odds ratio; CI: confidence interval. 
Table 4. - Associations between wheezing and reported intake of antioxidant nutrients

\begin{tabular}{|c|c|c|c|c|}
\hline \multirow[b]{2}{*}{ Tertile of intake } & \multicolumn{2}{|c|}{ All cases $(n=94)$} & \multicolumn{2}{|c|}{ Cases with current wheeze $(n=66)$} \\
\hline & $\begin{array}{l}\text { Proportion of } \\
\text { cases (controls) }\end{array}$ & $\begin{array}{c}\text { OR }(95 \% \mathrm{CI})^{*} \\
\text { p-value }\end{array}$ & $\begin{array}{l}\text { Proportion of } \\
\text { cases (controls) }\end{array}$ & $\begin{array}{c}\text { OR (95\% CI)* } \\
\text { (p-value) }\end{array}$ \\
\hline \multicolumn{5}{|l|}{ Vitamin A $\mu \mathrm{g}$} \\
\hline High & $37(32)$ & 1.0 & $40(32)$ & 1.0 \\
\hline Middle & $38(31)$ & $1.11(0.57-2.14)$ & $36(32)$ & $0.94(0.44-2.04)$ \\
\hline Low & $25(37)$ & $\begin{array}{c}0.58(0.29-1.18) \\
\quad(\mathrm{p}=0.144)\end{array}$ & $24(36)$ & $\begin{array}{c}0.59(0.26-1.33) \\
\quad(p=0.212)\end{array}$ \\
\hline \multicolumn{5}{|l|}{$\beta$-carotene $\mu \mathrm{g}$} \\
\hline High & $32(34)$ & 1.0 & $32(35)$ & 1.0 \\
\hline Middle & $33(34)$ & $0.93(0.47-1.82)$ & $32(34)$ & $0.93(0.42-2.03)$ \\
\hline Low & $35(32)$ & $\begin{array}{l}0.88(0.45-1.75) \\
\quad(p=0.719)\end{array}$ & $36(31)$ & $\begin{array}{c}0.89(0.40-1.94) \\
(\mathrm{p}=0.761)\end{array}$ \\
\hline \multicolumn{5}{|l|}{ Vitamin $\mathrm{C} \mathrm{mg}$} \\
\hline High & $28(36)$ & 1.0 & $23(37)$ & 1.0 \\
\hline Middle & $31(35)$ & $1.12(0.56-2.21)$ & $29(34)$ & $1.28(0.55-2.98)$ \\
\hline Low & $41(29)$ & $\begin{array}{c}1.45(0.71-2.97) \\
(\mathrm{p}=0.341)\end{array}$ & $48(29)$ & $\begin{array}{c}2.06(0.88-4.82) \\
\quad(p=0.090)\end{array}$ \\
\hline \multicolumn{5}{|l|}{ Vitamin E mg } \\
\hline High & $27(36)$ & 1.0 & $27(38)$ & 1.0 \\
\hline Middle & $29(36)$ & $1.03(0.51-2.09)$ & $26(36)$ & $1.06(0.45-2.49)$ \\
\hline Low & $44(28)$ & $\begin{array}{c}1.93(0.79-4.72) \\
(\mathrm{p}=0.186)\end{array}$ & $47(26)$ & $\begin{array}{c}4.02(1.30-12.42) \\
\quad(p=0.031)\end{array}$ \\
\hline
\end{tabular}

*: odds ratio (OR) derived from logistic regression analyses are for lower compared with upper tertile including adjustment for smoking habit (never, former, current), atopy (none, any one, any two or all three measures positive), family history (none, one or more than one affected relative), social class (nonmanual, manual), sex (male, female) and total energy intake. CI: confidence interval.

concentrations and $\alpha$-tocopherol:triglyceride ratio. Higher plasma triglyceride levels were independently associated with increased risk. In general, the relationships were more significant when the analyses were performed with current wheeze as the outcome. Analysis based on natural log-transformed values or quantiles of the plasma measurements did not alter the interpretation of the results presented.

Due to the potential for intercorrelation between social class, smoking habit and nutrient intake, stratified analyses

Table 5. - Association between plasma concentrations and adult onset wheeze

\begin{tabular}{lcc}
\hline & \multicolumn{2}{c}{ Odds ratio $(95 \% \mathrm{CI}) *$ per unit } \\
\cline { 2 - 3 } & $\begin{array}{c}\text { All cases } \\
(\mathrm{n}=86)\end{array}$ & $\begin{array}{c}\text { Cases with current } \\
\text { wheeze }(\mathrm{n}=59)\end{array}$ \\
\hline Retinol & $1.29(0.95-1.74)$ & $1.32(0.94-1.86)$ \\
& $\mathrm{p}=0.100$ & $\mathrm{p}=0.113$ \\
$\beta$-carotene & $0.35(0.12-1.01)$ & $0.66(0.30-1.45)$ \\
Ascorbate & $\mathrm{p}=0.306$ & $\mathrm{p}=0.053$ \\
& $0.99(0.97-1.00)$ & $0.98(0.96-0.99)$ \\
$\alpha$-tocopherol & $\mathrm{p}=0.055$ & $\mathrm{p}=0.017$ \\
& $1.03(0.99-1.07)$ & $1.03(0.99-1.08)$ \\
Triglycerides & $\mathrm{p}=0.105$ & $\mathrm{p}=0.135$ \\
& $1.43(1.08-1.89)$ & $1.56(1.12-2.18)$ \\
$\alpha$-tocopherol: & $\mathrm{p}=0.013$ & $\mathrm{p}=0.008$ \\
triglyceride ratio $\left(\log _{\mathrm{e}}\right)$ & $0.45(0.24-0.83)$ & $0.34(0.16-0.72)$ \\
\hline
\end{tabular}

*: odds ratio per unit derived from logistic regression analyses are adjusted for smoking habit (never, former, current), atopy (none, any one, any two or all three measures positive), family history (none, one or more than one affected relative), social class (nonmanual, manual) and sex (male, female). CI: confidence interval. were carried out to examine whether there were interactions of social class and smoking with vitamin $\mathrm{C}$ and $\mathrm{E}$ intakes and plasma levels. The independent associations of vitamin $\mathrm{C}$ and $\mathrm{E}$ intakes with current wheeze differed by social class (table 6). Although an inverse association of vitamin $\mathrm{C}$ and $\mathrm{E}$ intake with current wheeze was noted in both cases, the effect was significant only in the manual class. The analysis for plasma levels of vitamins $\mathrm{C}, \alpha-$ tocopherol:triglyceride ratio stratified by social class showed a similar pattern (table 7).

The independent associations of vitamin $\mathrm{C}$ and $\mathrm{E}$ intake with current wheeze also differed by smoking habit (table 8 ), the only significant relationship being among current smokers. The analyses in the small smoking categories produced wide CIs. The analyses for plasma levels of ascorbate and $\alpha$-tocopherol:trigyceride ratio stratified by smoking habit showed a similar pattern (table 9).

\section{Discussion}

The aim of this study was to test the hypothesis that lower antioxidant intakes and lower plasma antioxidant concentrations are associated with adult-onset wheezing illness. These results showed that intakes of vitamin $\mathrm{E}$ and plasma levels of vitamin $C$ and $\alpha$-tocopherol:triglyceride ratio were inversely related to adult-onset wheeze even after adjustment for other established risk factors. In analyses stratified by social class and smoking, intakes of vitamin $\mathrm{C}$ and $\mathrm{E}$ and plasma levels of $\alpha$-tocopherol: triglyceride ratio were inversely related to current wheeze only in the manual worker social class and among current smokers. The importance of vitamin $\mathrm{C}$ and $\mathrm{E}$ intake in wheezing illness among manual workers and smokers may be explained, in part, by the tendency of these groups to 
Table 6. - Associations between current wheezing (i.e. wheezing in the previous year) and reported intakes of vitamins $\mathrm{C}$ and $\mathrm{E}$ by social class

\begin{tabular}{|c|c|c|c|c|}
\hline \multirow[b]{2}{*}{ Tertile of intake } & \multicolumn{2}{|c|}{ Manual (n=120) } & \multicolumn{2}{|c|}{ Nonmanual $(n=136)$} \\
\hline & $\begin{array}{c}\text { Proportion of } \\
\text { cases (controls) }\end{array}$ & $\begin{array}{c}\text { OR }(95 \% \mathrm{CI})^{*} \\
\text { (p-value) }\end{array}$ & $\begin{array}{c}\text { Proportion of } \\
\text { cases (controls) }\end{array}$ & $\begin{array}{c}\text { OR }(95 \% \mathrm{CI})^{*} \\
(\mathrm{p}-\text {-value })\end{array}$ \\
\hline \multicolumn{5}{|l|}{ Vitamin $\mathrm{C}$} \\
\hline High & $14(29)$ & 1.0 & $41(43)$ & 1.0 \\
\hline Middle & $27(36)$ & $2.19(0.57-8.44)$ & $32(32)$ & $0.83(0.25-2.71)$ \\
\hline Low & $59(35)$ & $\begin{array}{c}4.19(1.08-16.22) \\
(p=0.034)\end{array}$ & $27(25)$ & $\begin{array}{c}1.44(0.38-5.48) \\
\quad(p=0.693)\end{array}$ \\
\hline \multicolumn{5}{|l|}{ Vitamin E } \\
\hline High & $16(33)$ & 1.0 & $50(41)$ & 1.0 \\
\hline Middle & $25(32)$ & $1.72(0.44-6.71)$ & $27(40)$ & $0.54(0.15-1.90)$ \\
\hline Low & $59(35)$ & $\begin{array}{c}6.59(1.36-31.89) \\
(p=0.019)\end{array}$ & 23 (19) & $\begin{array}{c}2.91(0.46-18.46) \\
(p=0.658)\end{array}$ \\
\hline
\end{tabular}

*: odds ratio (OR) derived from logistic regression analyses are for lower compared with upper tertile including adjustment for smoking habit (never, former, current), atopy (none, any one, any two or all three measures positive), family history (none, one or more than one affected relative), sex (male, female) and total energy intake. CI: confidence interval.

have lower intakes of antioxidants, greater oxidant exposure and higher metabolic turnover of antioxidants [3235]. It has previously been shown by this group that the relationship between social class and adult onset wheeze may be partially explained by greater cigarette exposure in the manual class [17]. The stratified analysis identified groups of subjects who, owing to the interrelationships of various lifestyle factors including diet, smoking and environmental or occupational exposures common to the manual worker social class, may be particularly susceptible to wheezing illness in adulthood.

The results of the present study are consistent with these findings with respect to bronchial reactivity in a separate population [12] and add support to accumulating epidemiological evidence that intakes of vitamins $\mathrm{C}$ and $\mathrm{E}$ may have important effects on the respiratory system. Respiratory symptoms [10], diagnoses of asthma or chronic bronchitis [10] and impaired lung function [9] have been found to be related to low dietary fruit and fruit juice intake. While factors associated with fruit consumption other than vitamin $\mathrm{C}$ intake may have contributed to these findings, other studies which have quantified vitamin $\mathrm{C}$ intakes have reported positive associations with lung function in general populations in the UK [6] and the USA [8]. Wheezing in the previous year was inversely associated with serum

Table 7. - Associations between current wheezing (i.e. wheezing in the previous year) and plasma concentrations of vitamins $\mathrm{C}$ and $\mathrm{E}$ by social class

\begin{tabular}{lcc}
\hline & \multicolumn{2}{c}{ Odds ratio $(95 \% \mathrm{CI}) *$ per unit } \\
\cline { 2 - 3 } & $\begin{array}{c}\text { Manual } \\
(\mathrm{n}=112)\end{array}$ & $\begin{array}{c}\text { Nonmanual } \\
(\mathrm{n}=128)\end{array}$ \\
\hline Vitamin $\mathrm{C}$ & $0.98(0.95-1.00)$ & $0.98(0.95-1.00)$ \\
$\mathrm{p}=0.091$ & $\mathrm{p}=0.110$ \\
C-tocopherol: & $0.20(0.06-0.61)$ & $0.57(0.20-1.62)$ \\
triglyceride ratio $\left(\log _{\mathrm{e}}\right)$ & $\mathrm{p}=0.005$ & $\mathrm{p}=0.290$ \\
\hline
\end{tabular}

*: odds ratio per unit derived from logistic regression analyses are adjusted for smoking habit (never, former, current), atopy (none, any one, any two or all three measures positive), family history (none, one or more than one affected relative), social class (nonmanual, manual) and sex (male, female). CI: confidence interval. vitamin $\mathrm{C}$, but not dietary vitamin $\mathrm{C}$, in data from an American general population [11].

In comparison with vitamin $\mathrm{C}$, fewer studies have evaluated the relationship of vitamin $\mathrm{E}$ to pulmonary symptoms. In our study, lower vitamin E intake and lower plasma $\alpha$-tocopherol:triglyceride ratios were associated with increased risk of wheeze. Although the lower plasma $\alpha$-tocopherol:triglyceride ratio in cases reflects their higher triglyceride concentration compared with controls, the fact that tocopherol concentration will normally mirror increases in triglyceride level [36] suggests that a lower plasma $\alpha$-tocopherol:triglyceride ratio is indicative of poorer vitamin E status. Moreover, standardizing tocopherol with triglyceride-rich lipid in the plasma is more relevant to expression of values measured in nonfasted samples since it reflects postprandial changes in both the vitamin and the lipid. Other studies of vitamin $\mathrm{E}$ have provided conflicting results. In a random population survey of British adults which found a relationship between reported vitamin $\mathrm{E}$ intake and lung function, no independent effect was evident after accounting for vitamin C intake [6]. In that study, the magnitude of vitamin $\mathrm{E}$ estimates may have been diminished by the measurement error associated with the FFQ which, although adapted from a previously validated questionnaire, had not itself been validated. Another study showed no difference in plasma vitamin $\mathrm{E}$ between children with asthma and controls [37]. However, in an elderly British population, reduced intake of vitamin $\mathrm{E}$ was associated with poorer lung function, even after controlling for vitamin $\mathrm{C}$ [38] and in a large prospective American study of nurses, a protective effect of dietary vitamin $\mathrm{E}$ against adult-onset asthma was observed [13].

The biological effects of vitamins $\mathrm{C}$ and $\mathrm{E}$ are likely to be closely related. Together, ascorbate and $\alpha$-tocopherol play a central role in endogenous antioxidant defence systems. The $\mathrm{D}-\alpha$-tocopherol homologue of vitamin $\mathrm{E}$ is the most biologically potent lipophilic antioxidant in humans, and accounts for $\sim 90 \%$ of the vitamin $\mathrm{E}$ present in tissues [39]. It scavenges intermediate peroxyl radicals as a result of which phenoxyl radicals of $\alpha$-tocopherol are formed. Kinetic studies demonstrate an intracellular interaction between vitamin $\mathrm{E}$ and vitamin $\mathrm{C}$ whereby the membranebound oxidized vitamin $\mathrm{E}$ is regenerated non-enzymically 
Table 8. - Associations between current wheezing (i.e. wheezing in the previous year) and reported intakes of vitamins $\mathrm{C}$ and $\mathrm{E}$ by smoking habit

\begin{tabular}{|c|c|c|c|c|c|c|}
\hline \multirow[b]{2}{*}{ Tertile of intake } & \multicolumn{2}{|c|}{ Current smoker $(\mathrm{n}=88)$} & \multicolumn{2}{|c|}{ Former smoker $(\mathrm{n}=60)$} & \multicolumn{2}{|c|}{ Never smoker $(\mathrm{n}=108)$} \\
\hline & $\begin{array}{l}\text { Proportion of } \\
\text { cases (controls) }\end{array}$ & $\begin{array}{c}\text { OR (95\% CI)* } \\
\text { (p-value) }\end{array}$ & $\begin{array}{l}\text { Proportion of } \\
\text { cases (controls) }\end{array}$ & $\begin{array}{c}\text { OR (95\% CI)* } \\
\text { (p-value) }\end{array}$ & $\begin{array}{l}\text { Proportion of } \\
\text { cases (controls) }\end{array}$ & $\begin{array}{l}\text { OR (95\% CI)* } \\
\quad(p-\text {-value })\end{array}$ \\
\hline \multicolumn{7}{|l|}{ Vitamin $\mathrm{C}$} \\
\hline High & $14(32)$ & 1.0 & $21(43)$ & 1.0 & $41(36)$ & 1.0 \\
\hline Middle & $26(26)$ & $3.06(0.65-14.39)$ & $36(37)$ & $1.06(0.15-7.39)$ & $29(36)$ & $0.31(0.06-1.52)$ \\
\hline Low & $60(42)$ & $\begin{array}{c}4.68(1.05-20.92) \\
(p=0.049)\end{array}$ & $43(20)$ & $\begin{array}{c}5.35(0.59-48.43) \\
(p=0.161)\end{array}$ & $29(28)$ & $\begin{array}{c}0.44(0.08-2.52) \\
\quad(p=0.322)\end{array}$ \\
\hline \multicolumn{7}{|l|}{ Vitamin E } \\
\hline High & $17(36)$ & 1.0 & $36(46)$ & 1.0 & $41(35)$ & 1.0 \\
\hline Middle & $23(10)$ & $2.69(0.54-13.49)$ & $28(41)$ & $0.70(0.10-4.73)$ & $29(37)$ & $0.38(0.08-1.70)$ \\
\hline Low & $60(34)$ & $\begin{array}{c}27.53(3.56-213.10) \\
\quad(p=0.002)\end{array}$ & $36(13)$ & $\begin{array}{c}1.01(0.05-22.36) \\
(p=0.889)\end{array}$ & $29(28)$ & $\begin{array}{c}1.25(0.17-9.38) \\
(\mathrm{p}=0.760)\end{array}$ \\
\hline
\end{tabular}

*: odds ratio (OR) derived from logistic regression analyses are for lower compared with upper tertile including adjustment for atopy (none, any one, any two or all three measures positive), family history (none, one or more than one affected relative), social class (nonmanual, manual), sex (male, female) and total energy intake. CI: confidence interval.

by ascorbate at the membrane cytosol interface [40]. The biological requirements for vitamin $\mathrm{E}$ and vitamin $\mathrm{C}$ depend in part on the level of exposure to exogenously and endogenously produced reactive oxygen species. Any synergism between $\alpha$-tocopherol and ascorbic acid will be dependent on their relative concentrations in body fluids and tissues. In addition to a reduction in intake, the lower plasma $\alpha$-tocopherol status of cases in the present study may reflect a preferential mobilization of vitamin $\mathrm{E}$ towards tissues with the greatest requirement, e.g. the lungs. The level of vitamin $\mathrm{E}$ in the lungs of animals chronically exposed to smoke has repeatedly been shown to be 2-3 times higher than in the lungs of controls, which may reflect increased uptake and/or mobilization from body stores [41]. In animal models, regulation of vitamin $\mathrm{E}$ uptake by pulmonary tissues is believed to be controlled by the extent of exposure to oxidative stress. A similar regulation of vitamin $\mathrm{C}$ uptake might be postulated in humans, in whom alveolar macrophages of smokers have a higher total ascorbate content and an enhanced ability to accumulate ascorbate in vitro [42]. A study on human neutrophil ascorbate accumulation reinforces the hypothesis that maintenance of high intracellular ascorbate concentration at the expense of plasma ascorbate preserves the reducing potential of the cell [43]. The findings of this study could be explained by enhanced $\alpha$-tocopherol and ascorbate uptake by oxidatively stressed tissue resulting in lower plasma ascorbate concentrations in cases. In the present study, no independent associations for vitamin A or $\beta$-carotene or total plasma antioxidant capacity were found, again suggesting that the mechanism may be specific to vitamins $E$ and $C$ rather than a general antioxidant effect.

A further question raised by this study is whether or not the higher fat intakes and plasma lipid levels among the cases compared with controls may themselves have a direct influence on the risk of wheezing illness. Possible links between lung disease and fat intake may depend not only on the total amount of fat intake, but also on its nature. A relationship between high total fat intake and bronchial hyperresponsiveness has previously been observed in a different population to the present study [12]. BLACK and SHARPE [44] have proposed that the increase in asthma in recent years may be attributed to a change in the pattern of dietary polyunsaturated fatty acid (PUFA) intake with an increase in consumption of 6 PUFAs, such as linoleic acid, and a decrease in $\omega-3$ PUFAs, such as linolenic acid, promoting allergic sensitization. Others have suggested that a high intake of dietary $\omega-3$ fatty acids, as fish oils, protects against smoking-related chronic obstructive pulmonary disease (COPD) [45] and high oily fish consumption has also been associated with reduced asthma prevalence in children [46]. However, the effects may be relatively weak [11] and as BRITTON [47] has pointed out, it is possible that confounding by higher intake of antioxidant vitamins such as vitamin $\mathrm{C}$ in association with fish may explain the observed relationships.

Table 9. - Associations between current wheezing (i.e. wheezing in the previous year) and plasma concentrations of vitamins $\mathrm{C}$ and $\mathrm{E}$ by smoking habit

\begin{tabular}{lccc}
\hline & \multicolumn{2}{c}{ Relative risk: adjusted odds ratio $(95 \% \mathrm{CI}) *$ per unit } \\
\cline { 2 - 4 } & $\begin{array}{c}\text { Current smoker } \\
(\mathrm{n}=79)\end{array}$ & $\begin{array}{c}\text { Former smoker } \\
(\mathrm{n}=56)\end{array}$ & $\begin{array}{c}\text { Never-smoker } \\
(\mathrm{n}=105)\end{array}$ \\
\hline Vitamin $\mathrm{C}$ & $\begin{array}{c}0.95(0.92-0.98) \\
\mathrm{p}=0.003\end{array}$ & $\begin{array}{c}0.99(0.96-1.03) \\
\mathrm{p}=0.608\end{array}$ & $\begin{array}{c}1.02(0.98-1.05) \\
\mathrm{p}=0.345\end{array}$ \\
$\alpha$-tocopherol:triglyceride ratio $\left(\log _{\mathrm{e}}\right)$ & $\begin{array}{c}0.29(0.09-0.94) \\
\mathrm{p}=0.039\end{array}$ & $\begin{array}{c}0.18(0.03-1.06) \\
\mathrm{p}=0.058\end{array}$ & $\begin{array}{c}1.36(0.31-5.98) \\
\mathrm{p}=0.686\end{array}$ \\
\hline
\end{tabular}

*: odds ratios per unit derived from logistic regression analyses are adjusted for atopy (none, any one, any two or all three measures positive), family history (none, one or more than one affected relative), social class (nonmanual, manual) and sex (male, female). CI: confidence interval. 
Potential limitations of the present study include the case definition used, possible inaccuracies in intake estimates and the difficulty of determining temporal relationships between intakes and symptoms. Cases were defined based on self-reported wheeze rather than specific clinical or diagnostic labels. It is believed, however, that the broad case definition is informative and valid and that use of a more restricted definition such as doctor diagnosed asthma or COPD would be associated with several limitations. These include concurrent diagnoses of more than one obstructive airways disease [48], diagnostic bias in relation to perceived risk factors $[49,50]$, underdiagnosis of characteristic symptoms $[49,51]$ and under-reporting of diagnoses by subjects [52]. The accuracy of intake estimates can be considered in relation to the other findings of the present study. In this population, the mean energy intake to basal metabolic rate ratios were $>1.35$, the cut-off considered to be the lowest value for habitual energy intake compatible with life [26]. In addition, the intake values for vitamins $C, E$ and $\beta$-carotene correlated significantly and at levels established in the literature [53] with corresponding blood concentrations, demonstrating the ability of the questionnaire to reflect variation in diet in this population. These findings suggest that the intake values were not unduly affected by under-reporting bias and support the validity of the questionnaire as a measure of antioxidant intake. It was not possible to establish the temporal relationship between the nutrient exposure and the occurrence of wheeze in this study. Intake was evaluated in the preceding year, while the relevant exposure in the development of wheeze is likely to be more long-term. There is a possibility that subjects may have changed their dietary or supplemental intake when they developed symptoms, thus influencing the diet-disease relationship. Positive associations between vitamins $\mathrm{C}$ and $\mathrm{E}$ from supplements and adult-onset wheeze were reported in the study of American nurses and this appeared to be explained by the nurses initiating use of supplements with onset of symptoms [13]. The proportion of cases and controls taking supplements in this study was comparable with that reported in other British populations [32].

It is concluded that vitamin $\mathrm{C}$ and $\mathrm{E}$ consumption in adulthood is inversely associated with adult-onset wheeze, the effect being important in the manual social class and among current smokers. A specific role for these vitamins is supported by plasma measurements and the lack of relationship of wheeze to total antioxidant capacity. Understanding the relationships between diet, socioeconomic status and smoking habit may permit the formulation of strategies for prevention and thus contribute to a reduction in the risk of wheezing illness in highly susceptible groups. Future work is required to elaborate the mechanisms of the response and to establish whether similar patterns are seen in children in whom the prevalence of wheezing illnesses has undergone a dramatic increase.

Acknowledgements. The authors thank S. MacIntyre, D. Oldman and E. Zanre for co-operation in tracing the subjects; B. Calder for secretarial support; the field staff for assistance with data collection; G. Henderson, A. Scaife and M. Byers for technical assistance and D. Grubb for analysis of food frequency data.

\section{References}

1. Crystal RG. Oxidants and respiratory tract epithelial injury: pathogenesis and strategies for therapeutic intervention. Am J Med 1991; 91: 39S-44S.

2. Ninan TK, Russell G. Respiratory symptoms and atopy in Aberdeen schoolchildren: evidence from two surveys 25 years apart. Br Med $J$ 1992; 304: 873-875.

3. Britton J. Asthma's changing prevalence: establishing the true figures is difficult. Br Med $J$ 1992; 304: 857-858.

4. Ministry of Agriculture. Household Food Consumption and Expenditure. Annual reports of the National Food Survey Committee. London, 1990; pp. 1961-1990.

5. Seaton A, Godden DJ, Brown K. Increase in asthma: a more toxic environment or a more susceptible population? Thorax 1994; 49: 171-174.

6. Britton JR, Pavord ID, Richards KA, et al. Dietary antioxidant vitamin intake and lung function in the general population. Am J Respir Crit Care Med 1995; 151: 13831387.

7. Morabia A, Sorenson A, Kumanyika DK, et al. Vitamin A, cigarette smoking and airway obstruction. Am Rev Respir Dis 1989; 140: 1312-1316.

8. Schwartz J, Weiss ST. Relationship between dietary vitamin $\mathrm{C}$ intake and pulmonary function in the first national health and nutrition examination survey (NHANES 1). Am J Clin Nutr 1994; 59: 110-114.

9. Strachan DP, Cox BD, Erzinclioglu SW, Walters DE, Whichelow MJ. Ventilatory function and winter fresh fruit consumption in a random sample of British adults. Thorax 1991; 46: 624-629.

10. Miedema I, Feskens EJM, Heederik D, Kromhout D. Dietary determinants of long-term incidence of chronic nonspecific lung diseases: the Zutphen study. Am J Epidemiol 1993; 138: 37-45.

11. Schwartz J, Weiss ST. Dietary factors and their relation to respiratory symptoms: the second national health and nutrition examination survey. Am J Epidemiol 1990; 132: $67-76$

12. Soutar A, Seaton A, Brown K. Bronchial reactivity and dietary antioxidants. Thorax 1997; 52: 166-170.

13. Troisi RJ, Willett WC, Weiss ST, Trichopoulos D, Rosner B, Speizer FE. A prospective study of diet and adult-onset asthma. Am J Respir Crit Care Med 1995; 151: 14011408.

14. Dawson B, Horobin G, Illsley R, Mitchell R. A survey of childhood asthma in Aberdeen. Lancet 1969; 1: 827830.

15. Godden DJ, Ross S, Abdalla M, et al. Outcome of wheeze in childhood: symptoms and pulmonary function 25 years later. Am J Respir Crit Care Med 1994; 149: 106-112.

16. Ross S, Godden DJ, Abdalla M, et al. Outcome of wheeze in childhood: the influence of atopy. Eur Respir J 1995; 8: 2081-2087.

17. Bodner C, Ross S, Douglas G, et al. The prevalence of adult onset wheeze: longitudinal study. $\mathrm{Br}$ Med J 1997; 314: 792-793.

18. Bodner $\mathrm{CH}$, Ross $\mathrm{S}$, Little $\mathrm{J}$, et al. Risk factors for adult onset wheeze: a case control study. Am J Respir Crit Care Med 1998; 157: 35-42.

19. New SA. An epidemiological investigation into the influence of nutritional factors on bone mineral density and bone metabolism. PhD Thesis, University of Aberdeen, 1995.

20. Hendrick DJ, Davies RJ, D'Souza MF, Pepys J. An analysis of skin prick test reactions in 656 asthmatic patients. Thorax 1975; 30: 2-8. 
21. Hess D, Keller HE, Oberlin B, Bonfanti R, Schuep W. Simultaneous determination of retinol, tocopherols, carotenes and lycopene in plasma by means of high-performance liquid chromatography on reversed phase. Int $J$ Vit Nutr Res 1991; 61: 232-238.

22. Beutler HO. Methods of Enzymatic Analysis Vol. VI. Weinheim, Basel, Verlag Chemie, 1984; pp. 376-385.

23. Miller NJ, Rice-Evans C, Davies MJ, Gopinathan V, Milner A. A novel method for measuring antioxidant capacity and its application to monitoring the antioxidant status in premature neonates. Clin Sci 1993; 84: 407-412.

24. Esterbauer H, Cheeseman KH. Determination of aldehydic lipid peroxidation products: malonaldehyde and 4hydroxynonenal. Meth Enzymol 1990; 186: 407-421.

25. Paglia DE, Valentine WN. Studies on the quantitative and qualitative characterization of erythrocyte glutathione peroxidase. J Lab Clin Med 1967; 70: 158-169.

26. Goldberg GR, Black AK, Jebb SA, et al. Critical evaluation of energy intake data using fundamental principles of energy physiology: 1 . Derivation of cut-off limits to identify under-recording. Eur J Clin Nutr 1991; 45: 569-581.

27. Crawley H. Food Portion Sizes. London, HMSO, 1988.

28. Holland B, McCance RA, Widdowson EH. McCance and Widdowson's the Composition of Foods. Cambridge, Royal Society of Chemistry, 1991.

29. Willett WC, Stampfer MJ. Total energy intake: implications for epidemiologic analyses. Am J Epidemiol 1986; 124: 17-27.

30. Hsieh CC, Maisonneuve P, Boyle P, MacFarlance GJ, Robertson C. Analysis of quantitative data by quartiles in epidemiologic studies: classification according to cases, noncases, or all subjects? Epidemiology 1991; 2: 137140.

31. Hosmer DW, Lemeshow S. Applied Logistic Regression. New York, Wiley, 1989.

32. Gregory J, Foster K, Tyler H, Wiseman M. The Dietary and Nutritional Survey of British Adults. London, HMSO, 1990.

33. Bolton-Smith C, Smith WCS, Woodward M, TunstallPedoe H. Nutrient intakes of different social-class groups: results from the Scottish Heart Health Study (SHHS). Br J Nutr 1991; 65: 321-335.

34. Stryker WS, Kaplan LA, Stein EA, Stampfer MJ, Sober A, Willett WC. The relation of diet, cigarette smoking and alcohol consumption to plasma beta-carotene and alphatocopherol levels. Am J Epidemiol 1988; 127: 283-296.

35. Kallner AB, Hartmann D, Hornig DH. On the requirements of ascorbic acid in man: steady-state turnover and body pool in smokers. Am J Clin Nutr 1981; 34: 13471355 .

36. Meydani M, Cohn JS, Macauley JB, et al. Postprandial changes in the plasma concentration of alpha- and gamma-tocopherol in human subjects fed a fat-rich meal supplemented with fat-soluble vitamins. $J$ Nutr 1989; 119: 1252-1258.
37. Powell CVE, Nash AA, Powers HJ, Primhak RA. Antioxidant status in asthma. Pediatr Pulmonol 1994; 18: 34-38.

38. Dow L, Tracey M, Villar A, et al. Does dietary intake of vitamins $\mathrm{C}$ and $\mathrm{E}$ influence lung function in older people? Am J Respir Crit Care Med 1996; 154: 1401-1404.

39. Burton GW, Ingold KU. Autooxidation of biological molecules. 1. The antioxidant activity of vitamin $\mathrm{E}$ and related chain breaking phenolic antioxidants in vitro. $J$ Am Chem Soc 1981; 103: 6472-6477.

40. Chan AC. Partners in defence, vitamin E and vitamin C. Can J Physiol Pharmacol 1993; 71: 725-731.

41. Chow CK. Cigarette smoking and oxidative damage in the lung. Ann NY Acad Sci 1993; 686: 289-298.

42. McGowan SE, Parenti CM, Hoidal JR, Niewoehner DE. Ascorbic acid content and accumulation by alveolar macrophages from cigarette smokers and nonsmokers. $J$ Lab Clin Med 1984; 104: 127-134.

43. Washko P, Rotrosen D, Levine M. Ascorbic acid transport and accumulation in human neutrophils. $J$ Biol Chem 1989; 264: 18996-19002.

44. Black PN, Sharpe S. Dietary fat and asthma: is there a connection? Eur Respir J 1997; 10: 6-12.

45. Shahar E, Folsom AR, Melnick SL, et al. Dietary n-3 polyunsaturated fatty acids and smoking-related chronic obstructive pulmonary disease. $N$ Engl J Med 1994; 331: 228-233.

46. Hodge L, Salome CM, Peat JK, Haby MM, Xuan W, Woolcock AJ. Consumption of oily fish and childhood asthma risk. Med J Aust 1996; 164: 137-140.

47. Britton J. Dietary fish oil and airways obstruction. Thorax 1995; 50: S11-S15.

48. Dodge R, Cline MG, Burrows B. Comparisons of asthma, emphysema, and chronic bronchitis: diagnoses in a general population sample. Am Rev Respir Dis 1986; 133: 981-986.

49. Dodge RR, Burrows B. The prevalence and incidence of asthma and asthma-like symptoms in a general population sample. Am Rev Respir Dis 1980; 122: 567-575.

50. Littlejohns P, Ebrahim S, Anderson R. Prevalence and diagnosis of chronic respiratory symptoms in adults. $B M J$ 1989; 298: 1556-1560.

51. Hahn DL, Beasley JW. Diagnosed and possible undiagnosed asthma: a Wisconsin Research Network (WReN) Study. J Fam Pract 1994; 38: 373-379.

52. McWhorter WP, Polis MA, Kaslow RA. Occurrence, predictors, and consequences of adult asthma: Nhanesi and follow-up survey. Am Rev Respir Dis 1989; 139: 721-724.

53. Bolton-Smith C, Casey CE, Gey KF, Smith WCS, Tunstall-Pedoe H. Antioxidant vitamin intakes assessed using a food-frequency questionnaire: correlation with biochemical status in smokers and non-smokers. Br J Nutr 1991; 65: 337-346. 